\title{
A Pandemia de Covid-19 e a Desigualdade Racial de Renda'
}

Pedro H. G. Ferreira de Souza²

\section{INTRODUÇÃO}

A desigualdade racial de renda é tão elevada quanto persistente no Brasil, não obstante os avanços observados entre os anos 1990 e o início da década passada (Ipea, 2013; Osorio, 2019). Depois disso pouca coisa mudou: tanto durante a crise de 2014-2016 quanto na lenta recuperação posterior a renda domiciliar per capita de pretos e pardos oscilou em torno de $50 \%$ da renda dos brancos (IBGE, 2019, p. 56).

Nesse contexto, a dimensão racial da pandemia de Covid-19 despertou justificadas preocupaçóes sanitárias e econômicas, em especial diante das evidências do seu impacto assimétrico entre brancos e negros nos Estados Unidos (Góes, Ramos e Ferreira, 2020), país em que - apesar de tudo - a desigualdade racial de renda é menor do que no Brasil (Andrews, 2015).

O objetivo deste texto é documentar quatro fatos estilizados acerca dos efeitos da pandemia sobre a desigualdade econômica entre brancos e negros, conforme apresentado a seguir.

1) A massa salarial dos negros caiu mais do que a dos brancos entre o primeiro e o segundo trimestres de 2020.

2) A eliminação de postos de trabalho afetou muito mais intensamente os negros e explica quase toda a queda mais acentuada da massa salarial para esse grupo.

3) Por focalizar os mais pobres, o Auxílio Emergencial beneficiou mais a população negra e, na média, provavelmente mais do que compensou a perda na remuneração do trabalho desse grupo.

4) A grande redução da desigualdade promovida pelo Auxílio Emergencial ocorreu sobretudo pela diminuição da desigualdade entre a população negra.

Para isso, o texto está organizado em três seções, incluindo esta introdução. A seção 2 usa dados da Pesquisa Nacional por Amostra de Domicílios Contínua (PNADC) trimestral, conduzida pelo Instituto Brasileiro de Geografia e Estatística (IBGE), para descrever os dois primeiros fatos estilizados mencionados anteriormente, enquanto a seção 3 recorre à PNAD-Covid, também feita pelo IBGE, para tratar dos dois últimos.

\section{A PANDEMIA E O MERCADO DE TRABALHO}

A PNADC permite monitorar a evolução trimestral da massa salarial, isto é, a soma das remunerações efetivas de todos os trabalhos de todos os indivíduos ocupados. Essa massa salarial, por definiçáo, equivale à multiplicação de três termos: o número de ocupados, a jornada média de trabalho e a remuneração média por hora trabalhada.

1. DOI: http://dx.doi.org/10.38116/bapi26art4

2. Técnico de planejamento e pesquisa na Diretoria de Estudos e Políticas Sociais (Disoc) do Ipea. E-mail: <pedro.ferreira@ipea.gov.br>. 
A variação da massa salarial de um trimestre para o outro pode ser decomposta pelo método de Shapley (Shorrocks, 2013) em três elementos análogos: i) o efeito emprego, dado pela variação no número de ocupados; ii) o efeito jornada, dado pela variação na média de horas trabalhadas por ocupado; e iii) o efeito salários, dado pela variação no salário médio por hora trabalhada. A soma dos três componentes equivale à variação total da massa salarial.

O gráfico 1 aplica essa decomposição para avaliar a variação percentual da massa salarial para negros e brancos entre o primeiro e o segundo trimestres de 2020. Para facilitar as comparaçóes, o gráfico também inclui a média dos resultados para o período de crise econômica (2014-2016) e os anos de lenta recuperação (2017-2019).

\section{GRÁFICO 1}

Brasil: decomposição de Shapley da variação da massa salarial real entre o primeiro e o segundo trimestres, por cor ou raça (2014-2020)

(Em \%)

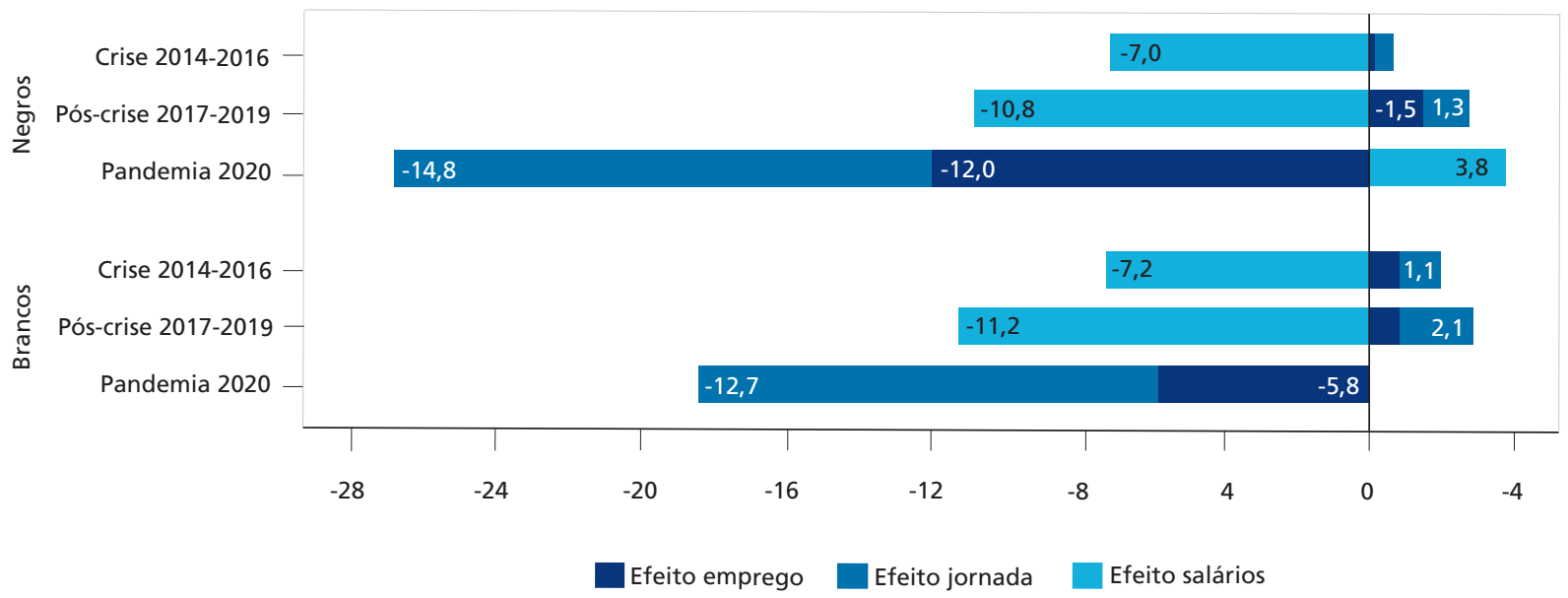

Fonte: Microdados da PNADC do primeiro e do segundo trimestres de 2014 a 2020.

Elaboração do autor.

Obs.: 1. Negros incluem pretos e pardos.

2. Amarelos, indígenas e indivíduos sem declaração de cor ou raça foram descartados da análise.

3. A massa salarial inclui remunerações efetivas de todos os trabalhos para todos os ocupados, exclusive indivíduos classificados como trabalhadores não remunerados familiares.

4. Os rótulos dos componentes com contribuição menor do que foram omitidos para facilitar a visualização do gráfico.

Nos três períodos houve diminuição da massa salarial real entre o primeiro e segundo trimestres, tanto entre negros quanto entre brancos. A magnitude da queda atual, contudo, foi muito maior devido à Covid-19, que prejudicou mais os negros. Assim, enquanto nos períodos anteriores a soma das remuneraçóes caiu entre $5 \%$ e $8 \%$, sem diferenças substantivas por cor ou raça, em 2020, a massa salarial dos brancos caiu 19\%, e a dos negros despencou ainda mais (23\%).

Os fatores por trás dessas reduções também foram diferentes. Anteriormente, a massa salarial costumava ser menor no segundo trimestre por causa do chamado efeito salários, ou seja, redução da remuneração efetiva média por hora, já que férias, abonos e afins são menos comuns entre abril e junho. 
Em 2020, esse padrão foi completamente diferente. A pandemia provocou quedas grandes tanto no número de postos de trabalho (efeito emprego) quanto na média de horas trabalhadas (efeito jornada), enquanto o efeito salários se tornou menos relevante.

A decomposição também mostra que a massa salarial dos negros caiu mais do que a dos brancos por causa do efeito emprego. Em bom português, os negros foram muito mais afetados por demissóes e pela eliminação de postos de trabalho, que provocaram queda de $12 \%$ da massa salarial entre trimestres, percentual cerca de duas vezes maior do que entre brancos. Em grau bem menor, o efeito jornada também contribuiu para a maior queda da massa salarial entre negros, enquanto o efeito salários atuou na direção oposta, o que indica que quem mais sofreu com demissóes ou redução da jornada foram os negros com menores salários.

Embora o tema mereça aprofundamento, esse padrão parece ser parcialmente explicado por diferenças nos tipos de vínculo de trabalho. Dado o histórico de desigualdade racial do Brasil, trabalhadores negros são majoritários entre assalariados informais e trabalhadores por conta própria, duas categorias fortemente atingidas pela eliminação de postos de trabalho na pandemia.

Seja como for, a Covid-19 introduziu uma divergência inédita na evolução da massa salarial de negros e brancos, atingindo os primeiros com muito mais força devido ao efeito emprego. Dessa forma, a eventual recuperação pós-pandemia deve beneficiar mais rapidamente os brancos, uma vez que novas contratações tendem a demorar mais do que simplesmente retomar jornadas de trabalho mais longas para aqueles que mantiveram seus vínculos empregatícios.

\section{O AUXÍLIO EMERGENCIAL E A DESIGUALDADE RACIAL DE RENDA}

Criado por iniciativa do Congresso em resposta à pandemia, o Auxílio Emergencial ampliou brutalmente a escala das transferências não contributivas no Brasil. O gasto mensal é quase dezoito vezes maior que o valor por mês tipicamente transferido pelo Programa Bolsa Família e corresponde a cerca de $20 \%$ da massa salarial total declarada na PNADC do primeiro trimestre de 2020. Com efeito, ao se tornar uma espécie de seguro-desemprego para trabalhadores informais, o Auxílio preencheu uma lacuna antiga do sistema brasileiro de proteção social e, assim, acabou por ter grande impacto na desigualdade racial mesmo sem recorrer a critérios explícitos de diferenciaçáo por cor ou raça.

O gráfico 2 mostra a composição da renda domiciliar per capita de negros e brancos de maio a julho de 2020, de acordo com a PNAD-Covid. ${ }^{3}$ Como normalmente ocorre em pesquisas domiciliares, os números do Auxílio Emergencial estão subestimados: a PNAD-Covid reporta totais mensais entre $\mathrm{R} \$ 23,6$ e $\mathrm{R}$ \$28,6 bilhóes para o período entre maio e junho, valores muito distantes dos R 46 bilhóes informados pelo Ministério da Cidadania para o mês de abril. ${ }^{4}$

Mesmo assim, o Auxílio Emergencial é imenso, e sua concentração nas camadas mais pobres implica maior cobertura da população negra. Em termos absolutos, em todos os meses, o valor per capita do Auxílio foi maior entre negros do que entre brancos. Em julho, por exemplo, era 48\%

3. A captação de rendimentos na PNAD-Covid não se restringe ao Auxílio Emergencial, abrangendo também outros auxílios relacionados ao coronavírus, o que, em tese, incluiria também benefícios pagos por estados e municípios. No entanto, 97\% das famílias que recebem algum benefício dessa natureza reportaram valores de $R \$ 600, R \$ 1.200$ ou $R \$ 1.800$, o que sugere fortemente que essa variável é composta quase exclusivamente pelo Auxílio Emergencial.

4. Infelizmente, até o momento, o portal VisData, do Ministério da Cidadania, traz informações apenas para abril. Os dados estão disponíveis em: <https://aplicacoes.mds.gov.br/sagi/vis/data3>. Acesso em: 8 set. 2020. Sobre a subestimação de programas sociais em pesquisas domiciliares, ver Souza (2013) e Souza et al. (2019). 
maior ( $\mathrm{R} \$ 158$, contra $\mathrm{R} \$ 107)$. Com efeito, quase dois terços dos benefícios foram para a população negra, que corresponde a cerca de $55 \%$ da população brasileira. Em termos relativos, o benefício variou entre $17 \%$ e $19 \%$ da renda total dos negros, contra apenas $6 \%$ ou $7 \%$ da renda dos brancos.

Com isso, o Auxílio Emergencial contribuiu para uma redução significativa da disparidade de renda média entre negros e brancos. Sem o Auxílio, a renda média dos brancos era quase $90 \%$ mais alta que a dos negros. Com o Auxílio, esse percentual cai para 70\%, valor ainda inaceitavelmente alto, evidentemente.

Devido a diferenças metodológicas entre a PNADC trimestral e a PNAD-Covid não é possível comparar com exatidão a renda distribuída pelo Auxílio com a perda salarial documentada na seção anterior. Tampouco é possível identificar na PNAD-Covid quais famílias receberiam as transferências do Programa Bolsa Família caso não existisse o Auxílio Emergencial.

Apesar dessas ressalvas, um exercício contrafactual bem simples - descrito no apêndice sugere que, em média, o Auxílio Emergencial pode ter mais do que compensado para os negros a perda salarial causada pela crise sanitária. Em outras palavras, é provável que a renda média dos negros entre maio e julho tenha sido maior do que seria em um mundo alternativo sem a pandemia. Isso não ocorreu entre os brancos por uma pequena margem, pelo menos na simulação feita com base na PNAD-Covid.

\section{GRÁFICO 2 \\ Brasil: composição da renda domiciliar per capita, por cor ou raça (2020)}

(Em R \$ julho/2020)

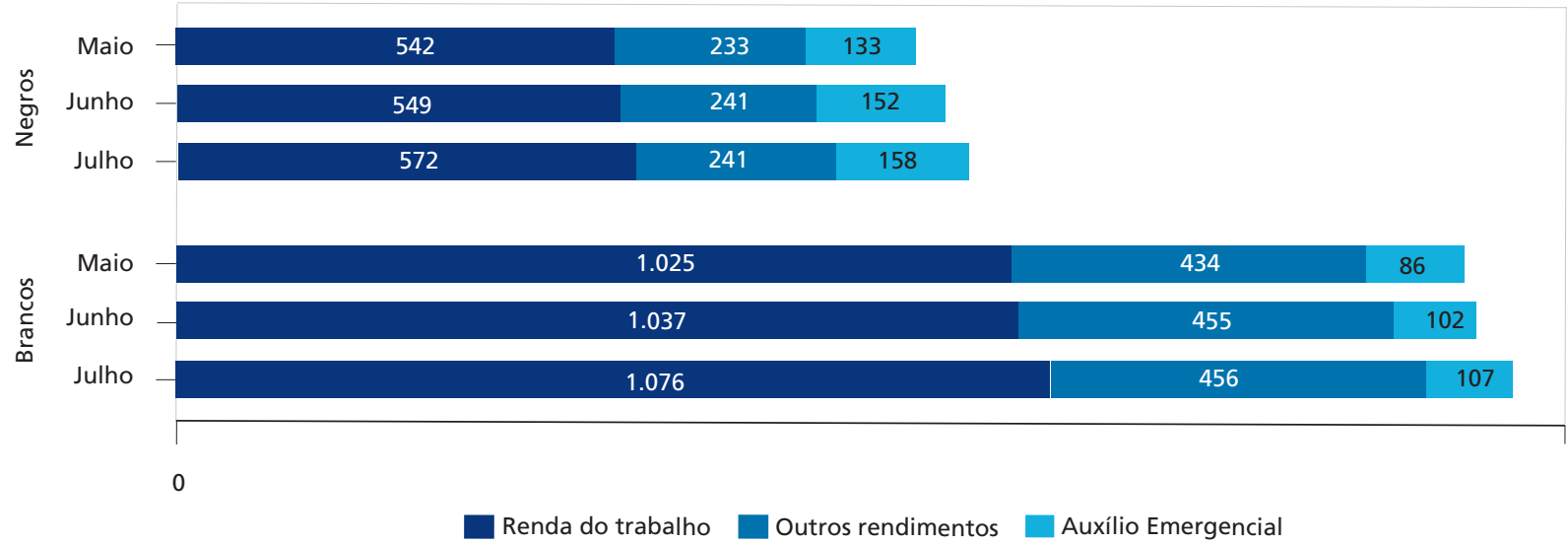

Fonte: Microdados da PNAD-Covid de maio, junho e julho de 2020.

Elaboração do autor.

Obs.: 1. Negros incluem pretos e pardos.

2. Amarelos, indígenas e indivíduos sem declaração de cor ou raça foram descartados da análise.

3. Rendimentos do trabalho efetivamente recebidos.

Para completar a descrição dos efeitos do Auxílio Emergencial sobre a desigualdade racial de renda, a tabela 1 apresenta a decomposição entre grupos do índice GE(0), também conhecido como o L de Theil. Em uma sociedade perfeitamente igualitária, isto é, em que todos os indivíduos recebem exatamente a mesma renda, o $\mathrm{GE}(0)$ seria igual a zero. Quanto mais alto seu valor, maior a desigualdade. 
TABELA 1

Brasil: decomposição por cor ou raça da desigualdade de renda per capita medida pelo índice GE(0) com e sem o Auxílio Emergencial (julho/2020)

\begin{tabular}{lccc}
\hline & Sem o Auxílio Emergencial & Com o Auxílio Emergencial & Variação (\%) \\
\hline Componente intragrupos & 0,482 & 0,324 & $-32,7$ \\
Negros & 0,250 & 0,148 & $-40,9$ \\
Brancos & 0,233 & 0,177 & $-24,0$ \\
Componente entre grupos & 0,043 & 0,031 & $-28,2$ \\
Desigualdade total & 0,526 & 0,356 & $-32,4$ \\
\hline
\end{tabular}

Fonte: Microdados da PNAD-Covid de maio, junho e julho de 2020

Elaboração do autor.

Obs.: 1. Negros incluem pretos e pardos.

2. Amarelos, indígenas e indivíduos sem declaração de cor ou raça foram descartados da análise.

3. A decomposição exclui indivíduos com renda per capita sem o Auxílio Emergencial igual a zero (7,4\% da população).

4. Rendimentos do trabalho efetivamente recebidos.

Decompor o GE(0) significa representar a desigualdade total como a soma da desigualdade entre grupos e da desigualdade interna de cada grupo ponderada pelo peso do grupo na população (Shorrocks, 1980). Se a renda média de brancos e negros fosse igual, o componente entre grupos na tabela 1 seria igual a zero. Quanto maior esse componente, maior a desigualdade de rendas médias entre os dois grupos. Raciocínio análogo vale para os componentes intragrupos: se todos os brancos (negros) tivessem a mesma renda per capita, o componente intragrupos entre brancos (negros) seria igual a zero; quanto maior a desigualdade de renda apenas entre os brancos (negros), maior o valor desse componente para esse grupo.

Em outras palavras, a decomposição permite definir a forma específica da desigualdade. Por exemplo, em uma sociedade de castas muito rígida quase toda a desigualdade total decorreria do componente entre grupos, enquanto, em uma sociedade meritocrática idealizada, esse componente seria igual a zero. Não há como apreender essas diferenças olhando apenas para a desigualdade total, que pode ser semelhante nos dois casos.

A tabela 1 dá a dimensão do enorme efeito redistributivo do Auxílio Emergencial. Ao comparar os resultados com e sem o programa, vemos que a desigualdade total é quase um terço menor quando contabilizamos o benefício. Mais ainda, todos os componentes se reduzem, indicando que o Auxílio Emergencial atuou para reduzir não só a desigualdade total, mas também a desigualdade entre brancos, entre negros e entre brancos e negros. Em termos relativos, sua principal contribuição se deu na diminuição da desigualdade entre os negros, que caiu quase $41 \%$. A desigualdade entre os brancos também recuou, mas em grau bem menor (24\%).

Esse padrão se repete nos meses anteriores (maio e junho) e também, com menos força, na decomposição do índice GE(1), ou T de Theil, desaparecendo só nas decomposiçóes de índices mais sensíveis ao topo da distribuição de renda, como o GE(2) e superiores.

O motivo para isso é a boa focalização do Auxílio Emergencial em um país historicamente marcado pela desigualdade racial, que faz com que políticas direcionadas aos mais pobres, de modo geral, também contribuam para reduzir disparidades de cor ou raça. Com efeito, sem o Auxílio, a taxa de pobreza entre negros para a linha de um quarto do salário mínimo chegaria a $25 \%$, quase o dobro dos 12,8\% registrados entre os brancos. Com o Auxílio, os dois percentuais caem muito e convergem, mas ainda assim a pobreza permanece maior entre negros $(7,7 \%$, contra $4,5 \%)$. Nem 
mesmo uma transferência do porte do Auxílio Emergencial é suficiente para eliminar diferenciais de cor ou raça na vulnerabilidade à pobreza.

A ressalva mais evidente é que esses efeitos são temporários. Previsto para durar apenas três meses, o Auxílio Emergencial integral foi prorrogado até agosto, mas em seguida entrou em fase de transição até sua eventual extinção em dezembro. Se, como dito, a recuperação for mais lenta para as camadas mais pobres da população negra, então, no médio prazo, tanto esse componente intragrupos quanto o componente entre grupos devem aumentar. A maneira mais imediata de combater essa tendência seria pela reformulação do PBF para torná-lo mais abrangente e generoso. Contudo, nenhuma das propostas em discussão chega perto da magnitude do Auxílio Emergencial, o que recomenda certo ceticismo quanto a seus possíveis efeitos distributivos, pelo menos em comparaçáo com os resultados da tabela 1. No médio prazo, permanece o desafio de incluir o enorme setor informal no sistema brasileiro de proteção social.

\section{REFERÊNCIAS}

ANDREWS, G. R. Desigualdade racial no Brasil e nos Estados Unidos, 1990-2010. Afro-Ásia, n. 51, p. 141-174, 2015.

GÓES, E. F.; RAMOS, D. O.; FERREIRA, A. J. F. Desigualdades raciais em saúde e a pandemia da Covid-19. Trabalho, Educaçáo e Saúde, v. 18, n. 3, p. 2-7, 2020.

IBGE - INSTITUTO BRASILEIRO DE GEOGRAFIA E ESTATÍSTICA. Síntese de indicadores sociais: uma análise das condiçôes de vida da população brasileira 2019. Rio de Janeiro: IBGE, 2019. IPEA - INSTITUTO DE PESQUSA ECONÔMICA APLICADA. Duas décadas de desigualdade e pobreza no Brasil medidas pela PNAD/IBGE. Brasília: Ipea, 2013. (Comunicados do Ipea, n. 159).

OSORIO, R. G. A desigualdade racial da pobreza no Brasil. Brasília: Ipea, 2019. (Texto para Discussão, n. 2487).

SHORROCKS, A. F. The class of additively decomposable inequality measures. Econometrica, v. 48, n.3, p. 613-625, 1980.

Decomposition procedures for distributional analysis: a unified framework based on the

Shapley value. Journal of Economic Inequality, v. 11, p. 99-126, 2013.

SOUZA, P. H. G. F. Uma metodologia para explicar diferenças entre dados administrativos e pesquisas amostrais, com aplicação para o Bolsa Família e o Benefício de Prestação Continuada na PNAD. Revista Brasileira de Estudos de Populaçáo, v. 30, n. 1, p. 299-315, 2013.

SOUZA, P. H. G. F. et al. Os efeitos do Programa Bolsa Família sobre a pobreza e a desigualdade: um balanço dos primeiros quinze anos. Brasília: Ipea, 2019. (Texto para Discussão n. 2499). 


\section{APÊNDICE}

Podemos estimar de forma bem simples qual seria a renda per capita de negros e brancos em um mundo alternativo sem pandemia se adotarmos três pressupostos principais, conforme a seguir.

1) A pandemia de Covid-19 reduziu os rendimentos do trabalho, mas não afetou os rendimentos de outras fontes.

2) A massa salarial observada na Pesquisa Nacional por Amostra de Domicílios (PNAD)-Covid em maio, junho e julho reflete as quedas percentuais vistas no gráfico 1 .

3) Sem pandemia, a massa salarial na PNAD-Covid refletiria quedas percentuais idênticas à média de 2017 a 2019.

A rigor, todos esses pressupostos são falsos: é evidente que a pandemia prejudicou alguns rendimentos de outras fontes (como aluguéis), a PNAD-Covid e a Pesquisa Nacional por Amostra de Domicílios Contínua (PNADC) trimestral têm diferenças conceituais e operacionais que prejudicam a comparação direta e, no limite, houve crescimento da renda do trabalho entre maio e julho, então obviamente o efeito da pandemia variou ao longo do tempo.

Ainda assim, são pressupostos plausíveis que facilitam a construção de contrafactuais imprecisos, mas que ilustram a magnitude do Auxílio Emergencial. Com base neles, a renda per capita contrafactual de negros e brancos seria:

$$
y_{\text {contrafactual }}=\left(\frac{1+\Delta_{2017-19}}{1+\Delta_{2020}}\right) y_{\text {trabalho }}+y_{\text {outras }}
$$

Em que $\Delta_{2017-2019}$ é o valor médio entre 2017 e 2019 da variação percentual da massa salarial entre o primeiro e o segundo trimestres, conforme indicado pela PNADC; $\Delta_{2020}$ é a variação percentual da massa salarial observada em 2020; $y_{\text {trabalho }}$ e $y_{\text {outras }}$ são, respectivamente, a renda média per capita do trabalho e de outras fontes.

A tabela A.1 apresenta os parâmetros utilizados e os resultados por cor ou raça. Nos três meses cobertos pela PNAD-Covid até aqui, a renda contrafactual dos negros é menor do que a renda observada, enquanto o oposto se dá entre os brancos. Dados os pressupostos citados, esses resultados sugerem que só a renda per capita dos negros com o Auxílio Emergencial foi um pouco maior do que seria em um mundo alternativo sem pandemia. 
TABELA A. 1

Brasil: parâmetros para construção do rendimento per capita contrafactual por cor ou raça (2020)

\begin{tabular}{|c|c|c|c|c|c|c|}
\hline & \multicolumn{3}{|c|}{ Parâmetros } & \multicolumn{2}{|c|}{ Renda per capita ( $\mathrm{R} \$$ ) } & \multirow[b]{2}{*}{ Variação (\%) } \\
\hline & $\frac{1+\Delta_{2017-19}}{1+\Delta_{2020}}$ & Trabalho (R\$) & Outras rendas (R\$) & Observado & Contrafactual & \\
\hline \multicolumn{7}{|c|}{ Negros } \\
\hline Maio & 1,194 & 542 & 233 & 908 & 880 & $-3,0$ \\
\hline Junho & 1,194 & 549 & 241 & 943 & 897 & $-4,9$ \\
\hline Julho & 1,194 & 572 & 241 & 971 & 923 & $-4,9$ \\
\hline \multicolumn{7}{|c|}{ Brancos } \\
\hline Maio & 1,125 & 1.025 & 434 & 1.546 & 1.588 & 2,7 \\
\hline Junho & 1,125 & 1.037 & 455 & 1.594 & 1.621 & 1,7 \\
\hline Julho & 1,125 & 1.076 & 456 & 1.640 & 1.668 & 1,7 \\
\hline & \multicolumn{6}{|c|}{$\begin{array}{l}\text { Fonte: Microdados da PNADC trimestral dos primeiros e segundos trimestres de } 2017 \text { a } 2002 \text { e da PNAD-Covid de maio, junho e julho de } 2020 \\
\text { Elaboração do autor. } \\
\text { Obs.: 1. Negros incluem pretos e pardos. } \\
\text { 2. Amarelos, indígenas e indivíduos sem declaração de cor ou raça foram descartados da análise. } \\
\text { 3. Valores em reais deflacionados para julho de } 2020 \text {. } \\
\text { 4. } \Delta_{2017-19} \text { é a média entre } 2017 \text { e } 2019 \text { da variação percentual da massa salarial entre o primeiro e segundo trimestres, de acordo com a } \\
\text { PNADC; } \Delta_{2020} \text { é a variação entre trimestres observada em } 2020 \text {. }\end{array}$} \\
\hline
\end{tabular}

